1 Universidade Federal de São Paulo (Unifesp) - Baixada Santista (SP), Brasil.

vargasdias@hotmail.com

2 Universidade Federal de São Paulo (Unifesp), Programa de Residência Multiprofissional em Atenção à Saúde (PRMAS)

- Baixada Santista (SP),

Brasil.

alessandrakeyth@gmail.com

3 Universidade Federal de São Paulo (Unifesp)

- Baixada Santista (SP),

Brasil.

sylviabatista@unifesp.br

${ }^{4}$ Sem vínculo institucional. isiscasanova@gmail.com

\section{A tutoria no processo de ensino- aprendizagem no contexto da formação interprofissional em saúde}

\author{
Mentoring in the teaching-learning process in the context of \\ interprofessional education in health
}

leda Maria Ávila Vargas Dias', Alessandra Keyth Pereira², Sylvia Helena Souza da Silva Batista ${ }^{\mathbf{3}}$, Isis Alexandrina Casanova ${ }^{4}$

RESUMO O objetivo deste estudo qualitativo é analisar a configuração de um Programa de Residência Multiprofissional em Saúde, na perspectiva dos tutores, versando sobre o processo de ensino-aprendizado no contexto da formação interdisciplinar e interprofissional. Os dados coletados em grupo focal e analisados por meio da análise de conteúdo permitiram a elaboração das seguintes categorias analíticas: Da efervescência a resiliência: a trajetória de um Programa de Residência Multiprofissional; A linha tênue da interdisciplinaridade; Os dois lados da interprofissionalidade. Na conclusão, evidencia-se que a experiência dos tutores se mostrou positiva apesar dos desafios impostos.

PALAVRAS-CHAVE Residência em saúde. Tutoria. Interprofissional.

ABSTRACT The purpose of this qualitative study is to analyze the configuration of a Multidisciplinary Residency Program in Health, from the perspective of the tutors, concerning the teaching-learning process in the context of interdisciplinary and interprofessional education. The data collected from focus groups and analyzed using content analysis allowed the elaboration of the following analytical categories: From effervescence to resilience: the trajectory of a Multidisciplinary Residency Program; A thin line of interdisciplinarity; The two sides of interprofessionality. In the conclusion, it is clear that the tutors' experience was positive despite the challenges imposed.

KEYWORDS Residency in health. Mentoring. Interprofessional. 


\section{Introdução}

Nos últimos anos, o Brasil passou por profundas transformações sociopolíticas-demográficas-epidemiológicas que se estenderão pelas próximas décadas. $\mathrm{O}$ modelo de assistência da saúde, acompanhando essas mudanças, foi também se alterando, e hoje o País dispõe do Sistema Único de Saúde (SUS), que consiste em uma formulação política e organizacional para o reordenamento dos serviços e ações de saúde estabelecidas pela Constituição Federal.

O objetivo desse sistema é prestar atenção à saúde da população por meio da promoção, proteção e recuperação da saúde, orientada pelos princípios organizativos da descentralização, regionalização, hierarquização, resolutividade, participação social e complementaridade do setor privado.

Apesar dos avanços quanto ao direito à saúde proporcionado pelo SUS e da ampla definição de seus determinantes, os desafios continuam emergindo e demandando um constante movimento de mudança no sentido de enfrentar as dificuldades. A falta de profissionais com formação adequada para atuar no SUS tem sido, ao lado de problemas de gestão e organização da atenção, um dos principais obstáculos para a melhoria da qualidade da atenção básica e para a efetividade do sistema (FELICIANO ET AL., 2013).

Novas estratégias dirigidas à transformação dos recursos humanos em saúde comprometidos pelos princípios de uma gestão humanizada e qualificada requerem vontade política, conhecimento, habilidades e processos organizativos para desenvolver serviços de saúde que melhorem as relações entre seus trabalhadores para que possam dar conta, de forma mais efetiva e respeitosa, das demandas de saúde advindas de seus cidadãos.

Nesse sentido, destacam-se as transformações no ensino e formação dos profissionais de saúde, impulsionadas pela implantação das Diretrizes Curriculares
Nacionais para os cursos de graduação, que trouxeram a demanda de repensar as estratégias de ensino e formação profissional, buscando programar ações que permitam às instituições formarem profissionais com perfil humanista, crítico e reflexivo, pautados em princípios éticos, capazes de atuar no processo saúde-doença com responsabilidade social e comprometidos com estratégias que visem à promoção da saúde, em seus diferentes níveis de atenção, tendendo às necessidades das políticas de atenção à saúde da população (COSTA NETO; BATISTA, 2013).

Como forma de incentivar a implementação das mudanças desejadas, algumas políticas indutoras foram lançadas, como o Programa Nacional de Reorientação da formação Profissional em saúde (Pró-Saúde); o Programa de Educação para o trabalho em Saúde (PET-Saúde) e as Residências Multiprofissionais em Saúde.

Em 2005, foi promulgada a Lei $n^{\circ}$ 11.129/05 que instituiu a Residência em Área Profissional de Saúde e criou a Comissão Nacional de Residência Multiprofissional em Saúde. Essa legislação versa sobre a modalidade de ensino em serviço nas áreas profissionais não médicas relacionadas com a saúde como forma de consolidar uma política de fortalecimento do SUS a partir das necessidades e realidades locais e regionais (COSTA NETO; BATISTA, 2013).

Nesse sentido, os Programas de Residência Multiprofissional em Saúde e em Área Profissional da Saúde se constituíram como uma proposta de cooperação interinstitucional para favorecer a inserção qualificada dos jovens profissionais da saúde no mercado de trabalho, particularmente no SUS.

A eficácia das ações de capacitação depende, fundamentalmente, de políticas que privilegiem essas ações, propiciando condições para que elas ocorram e promovam efetivamente mudanças nas práticas de saúde. A formação e a capacitação dos trabalhadores da saúde são reconhecidas como significativas em qualquer ramo da atividade 
produtiva, considerando a natureza do trabalho e suas relações. O desafio é que a proposta possibilite a formação de sujeitos autodeterminados e comprometidos sócio-historicamente com a produção do cuidado integral em saúde no plano individual e coletivo (FELICIANO ET AL., 2013).

A residência, modalidade de formação em pós-graduação latu sensu, caracteriza-se por ensino-aprendizagem em serviço, permeado pelos princípios e diretrizes do SUS, sendo a integralidade do cuidado um dos referenciais e o trabalho em equipe o princípio operador. Assim, a proposta é formar profissionais capazes de atuar em equipes multiprofissionais, de forma interdisciplinar e integrada, promovendo a agregação de saberes e práticas plurais no cotidiano dessas equipes, oferecendo um cuidado continuo à população (PEDREIRA ET AL., 2013).

Para tal, conta com a articulação de coordenadores, gestores, tutores, preceptores e docentes, que traçam uma proposta de ensino-aprendizagem no serviço. Estratégia que possibilita ao residente uma imersão nos locais de produção do cuidado e coloca aos trabalhadores o exercício contínuo de análise do sentido das práticas, propiciando o estabelecimento de ações questionadoras e de ressignificação, alicerces de uma aprendizagem.

Nesse contexto, a tutoria inscreve-se como uma das dimensões que demandam construção e aprendizagem na perspectiva de fortalecer a formação de residentes em saúde em consonância com os princípios do SUS, sendo delimitada como objeto de estudo nesta pesquisa que tem como objetivo: analisar a configuração de um Programa de Residência Multiprofissional em Saúde, na perspectiva dos tutores, versando sobre o processo de ensino-aprendizado no contexto da formação interdisciplinar, que corresponde ao universo de disciplinas teóricas, e interprofissional, concernente às questões práticas da profissão.

\section{Material e métodos}

O presente estudo tem um caráter qualitativo, visto que pretende conhecer, descrever e interpretar um fenômeno. A pesquisa qualitativa, segundo Minayo (2006), responde a questões muito particulares, preocupando-se com um nível de realidade que não pode ser quantificado, trabalhando com um universo que corresponde a um espaço mais profundo das relações, dos processos e dos fenômenos que não podem ser reduzidos à operacionalização de variáveis. Nesse tipo de pesquisa, o trabalho de campo se apresenta como uma possibilidade de conseguir não só uma aproximação com aquilo que se deseja conhecer e estudar, mas também de criar um conhecimento partindo da realidade presente no campo.

Na perspectiva da abordagem qualitativa, elegeu-se o estudo de caso como método a ser seguido. Este consiste em uma forma de aprofundar uma unidade individual, servindo para responder a questionamentos que o pesquisador não tem muito controle sobre o fenômeno estudado. O estudo de caso contribui para que se compreenda melhor os fenômenos individuais, processos organizacionais e políticos da sociedade. É uma ferramenta utilizada para que se entenda a forma e os motivos que levam a determinadas decisões (LÜDKE; ANDRÉ, 2008).

A produção dos dados foi realizada por meio de grupo focal. Essa técnica permite a obtenção de informações a partir de reuniões em grupo com pessoas significativas para o objeto de estudo. Tal método é utilizado internacionalmente para a estruturação de ações diagnósticas e levantamento de problemas; para o planejamento de atividades educativas, como objeto de promoção em saúde e meio ambiente; podendo ser utilizado também para a revisão do processo de ensino-aprendizagem (MCKINLAY, 2012).

Os encontros tiveram duração de duas horas em média, para que as condições dos participantes não interferissem nos 
objetivos da discussão. As reuniões com os grupos aconteceram em um ambiente que favoreceu o desenvolvimento das discussões propostas. Um Programa de Residência Multiprofissional em Saúde foi o cenário de estudo, e os participantes foram os tutores desse programa, os quais aceitarem de forma voluntária participar da pesquisa por meio da assinatura do Termo de Consentimento Livre Esclarecido.

A fase de análise dos dados tem a finalidade de estruturar os elementos obtidos para fornecer as respostas ao problema investigado, permitindo a interpretação dos dados que buscam o sentido mais amplo das respostas, com a ligação a outros conhecimentos previamente adquiridos (MINAYO, 2006). Nesse sentido, as anotações obtidas a partir dos grupos focais foram transcritas em sua íntegra, de forma atenta e minuciosa, para posterior interpretação e análise.

Elegeu-se a análise de conteúdo, por esta permitir a descoberta de diferentes núcleos de sentido que constituem a comunicação. Para Bardin (2009), esse tipo de análise consiste em um conjunto de técnicas de análise das comunicações, que utiliza procedimentos sistemáticos e objetivos de descrição do conteúdo das mensagens.

Assegurou-se que todas as etapas de realização do estudo fossem pautadas nas Diretrizes e Normas de Pesquisa em Seres Humanos, do Conselho Nacional de Saúde, contemplada na Resolução CNS $n^{0}$ 446/2012, atendendo aos aspectos éticos de pesquisa, tendo sido o projeto aprovado pelo Comitê de Ética em Pesquisas que envolvem seres humanos da Universidade Federal de São Paulo, com o parecer n ${ }^{0} 458.275$.

\section{Resultados}

Com o estudo, foi possível conhecer a experiência dos tutores em um Programa de Residência Multiprofissional no contexto da formação interdisciplinar e interprofissional, apresentada em três categorias analíticas, assim intituladas: 1 - Da efervescência a resiliência: a trajetória de um Programa de Residência Multiprofissional; 2 - A linha tênue da interdisciplinaridade; 3 - Os dois lados da interprofissionalidade e os seus desafios.

\section{1 - Da efervescência a resiliência: a trajetória de um Programa de Resi- dência Multiprofissional}

Essa categoria aborda o trajeto percorrido pelo Programa de Residência Multiprofissional, na visão dos tutores, revelando ousadias e desafios enfrentados. Eles relataram que, inicialmente, todos estavam muito envolvidos e empolgados com a proposta, apesar de não terem completa clareza do processo como um todo. Segundo os participantes, era motivador participar, inclusive denominaram esse período de efervescência.

Quando começamos todos estavam envolvidos, tinha muita articulação, os cenários de prática muito próximos da universidade, a turma chegou muito questionadora também, exigindo muito e a gente foi criando coisas numa empolgação boa. (E3).

O começo foi um período de efervescência, muito gostoso, todo mundo trocando, discutindo, muitas reuniões, o campus envolvido na proposta, estavam todos muito motivados. (E8).

Com o decorrer do processo, alguns nós críticos foram aparecendo, alguns conflitos foram surgindo e algumas pessoas foram se desmotivando e se afastando sem muitas discussões. A preceptoria foi se colocando como um grande desafio, a carga horária era sempre colocada em questão, tanto professores como residentes foram abandonando o Programa. Nesse cenário, prosseguiu-se, mas, segundo os participantes, muitas eram as críticas e cobranças. Os residentes já 
chegavam arredios e o distanciamento se acentuava.

Cada vez mais o distanciamento, o programa já não era mais do campus, nem dos cursos, muitas críticas, muita gente começou a sair da proposta, já naquela articulação de nada dando certo, enfim, muito difícil. (E5).

Tivemos problemas com a preceptoria, era preciso arrumar a casa, porque era muita indefinição, não tinha como dar certo mesmo. (E2).

De acordo com os depoimentos, isso tudo foi acontecendo no momento em que começava a existir uma maior aproximação da universidade com os campos cenários de práticas. Momento de construção de um espaço de discussão e articulação entre as instituições parceiras, universidade, Secretária Municipal de Saúde e hospital.

É interessante notar nos depoimentos que, ao passo que a crise foi se instalando, laços também foram se fortalecendo entre os parceiros, que já estavam bem mais articulados e próximos, sendo esse período denominado como um período de união.

Essa crise toda foi bem na hora em que a gente estava entrando mais nos cenários de práticas, nos espaços, fazendo costuras e acertando as coisas. E isso até que foi bom porque a gente de certa forma se uniu bastante na busca de não deixar o programa cair. (E3).

Os professores que ficaram foram tocando o programa porque a gente entendia que tinha benefícios e tinha muita coisa boa no processo. Fomos também ficando mais unidos. (E7).

Os participantes referem ter sido bastante cobrados em termos de preceptoria, tutoria, cenários, o que foi dificultando cada vez mais a continuidade do programa. Chegando a surgir a dúvida da viabilidade de se continuar ofertando vagas, isso suscitou uma intensa discussão no espaço acadêmico, que culminou em uma reorganização e na promessa de mais apoio e suporte ao programa, mas que não teria se concretizado efetivamente.

Com a decisão de dar continuidade ao programa, acreditando ser este um importante meio de formação de recursos humanos, uma nova turma foi aberta. Com alguma reestruturação, um novo período, denominado pelos participantes de período de resiliência, foi iniciado. Entretanto, apenas mais uma turma foi concluída, porque em difícil decisão tomada pelo colegiado, composto por tutores, preceptores, gestores e representantes dos residentes, o programa, em 2014 , deixou de oferecer novas vagas e concluiu suas atividades no ano de 2015.

Passados cinco anos de sua criação, com quatro turmas finalizadas, com entradas e saídas de áreas profissionais, de tutores, preceptores, gestores e residentes, importantes reflexões permeiam os depoimentos dos tutores, participantes deste estudo, ao refletirem sobre os erros e acertos do programa, havendo concordância em algumas questões e discordâncias em outras.

Eu acho que o modelo que a gente optou não foi o modelo mais adequado, porque onde dá certo é o serviço que toca, os coordenadores são profissionais do serviço e não que nem a gente que assumiu. (E4).

Eu não acho que aqui o modelo não deu certo, eu acho o que não deu certo foram às questões administrativas em volta desse modelo, eu não acho que esse modelo está errado. (E2).

Em um misto de certezas e incertezas, além da questão do modelo adotado pelo Programa, outras importantes questões foram levantadas, como a dificuldade da articulação em rede pelos próprios profissionais do serviço devido à falta de governabilidade do seu trabalho; as necessidade e 
peculiaridades de cada instituição parceira, o papel dos atores sociais do programa, principalmente tutores e preceptores.

A gente não tinha muita clareza de qual era a função do tutor, do preceptor, nem tinha saído ainda aquela lei que ia definir todos esses papeis, ali a gente não tinha clareza e foi se acertando aos poucos. (E6).

Acho que por não saber direito os papéis, inverteu um pouco e isso ficou meio confuso e acabou sendo passado para o residente que veio se vendo como da universidade, apenas utilizando o cenário. (E5).

Por fim, os participantes foram finalizando o relato da trajetória do programa e de como este foi se configurando ao longo desses cinco anos de existência. Reforçaram a questão de como algumas dificuldades foram sendo amenizadas no decorrer do tempo, além do fato de como o programa foi tomando um formato em que a vivência da tutoria tornou-se bastante positiva.

\section{2 - A linha tênue entre interdiscipli- naridade e interprofissionalidade}

Essa categoria ilustra a definição dos tutores para os termos interdisciplinaridade e interprofissionalidade. Apesar de em alguns momentos confundi-los e, até mesmo, não se sentirem seguros para definir o significado dos termos, referindo mais os objetivos e finalidades do que o próprio conceito, alguns tutores descrevem experiências importantes de interdisciplinaridade e interprofissionalidade que aconteceram no transcorrer da tutoria no programa de residência. Ao serem questionados sobre o que é a interdisciplinaridade, assim referiram:

A interdisciplinariedade, eu acho que chama para que a gente comungue dos diferentes saberes para poder de fato formar um profissional capacitado para cuidar dessa complexidade que é o fenômeno social de saúde, cuidado e doença. (E10).

A interdisciplinariedade é a mobilização de saberes diferentes para um mesmo fim, no caso cuidado. (E7).

A seguir, questionou-se sobre o que é a interprofissionalidade e, antes de responderem, em um ar de certa estranheza, pediram para rever o que tinha sido a pergunta anterior, e quase a totalidade referiu confundir esses termos.

Na hora que eu comecei a pensar, porque eu faço muita confusão, o que é interdisciplinar e interprofissional, para mim estão muito misturados. (E1).

Eu faço confusão, para mim estas duas estão muito relacionadas, interdisciplinariedade e interprofissionalidade estão na área dos saberes. (E4).

Se você me perguntar agora no final disso tudo que eu falei, se eu sei o que é interprofissional e interdisciplinar continuo na mesma confusão, faço muita pouca distinção. (E8).

Apesar de os conceitos interdisciplinaridade e interprofissionalidade serem discutidos já há alguns anos, estes ainda se mostram novos no que tange à questão conceitual, revelando um processo tímido de incorporação de conceitos. Além disso, esses termos, em alguns momentos, foram vistos como sinônimo de um trabalho em equipe humanizado.

A interprofissionalidade e a interdisciplinariedade tem também a ver com o trabalho em rede. Eu acredito que o interdisciplinar seria um trabalho que busca uma ajuda com o outro ou uma forma de trabalho partilhada!? (E2). 
Eu entendo por interdisciplinar, os profissionais trabalhando em conjunto, em equipe, seja nos atendimentos básicos ao paciente como em projetos terapêuticos singulares. (E1).

A proximidade do cuidado interprofissional com o trabalho pautado nos princípios e diretrizes do SUS parece contribuir para a dificuldade de distinguir os modos de trabalho de cada um. A característica de cooperação entre os profissionais, na interprofissionalidade, possibilita uma ampliação da visão e do cuidado com o usuário, porém não quer dizer que este cuidado seja humanizado. Da mesma forma que na cooperação somente partilhar o conhecimento pode não ser um trabalho em equipe. Alguns preceptores conhecem a essência do trabalho interprofissional, mesmo o confundindo, às vezes, com a interdisciplinaridade. Estes relataram experiências interprofissionais e ampliaram o conceito para além da técnica, discorrendo sobre a importância de se viver o interprofissionalismo.

A interprofissionalidade traz muito para a meIhora do cuidado, um exemplo é a nutrição, coisas simples que eu aprendi para o meu próprio cuidado. (E3).

$\mathrm{Na}$ interprofissionalidade a gente tem aqueles momentos onde as profissões se confluem, se juntam, se misturam mesmo, em que os conhecimentos são todos compartilhados. (E6).

O trabalho interprofissional é um trabalho em equipe poderoso, capaz de possibilitar mudanças e proporcionar amadurecimento pessoal e profissional. (E10).

O processo de internalização do conceito de interprofissionalidade começou a acontecer no decorrer da vivência dos tutores no programa em questão, corroborando a afirmação de Thiesen (2008), a qual coloca a interação entre alunos-professores-objeto de estudo como construtora das relações de sentido.

\section{3 - Os dois lados da interprofissiona- lidade e os seus desafios}

Essa categoria explicita as facilidades e dificuldades do trabalho interprofissional de acordo com os participantes do estudo. Os limites pessoais, profissionais e institucionais foram relatados pelos tutores como dificultadores, sendo a prática colaborativa e a troca de saberes apontadas como principais facilidades desse tipo de trabalho.

Nem todos estão no mesmo tempo, às vezes as pessoas podem estar paradas neste processo, pregadas nos seus lugares e podem não querem sair disso. (E3).

Talvez vocês possam me achar muito pessimista, mas eu não vejo facilidades, a gente tem é muita dificuldade neste caminho que demanda muita responsabilidade e investimento, não consigo ver facilidades. (E9).

Eu vejo que até temos dificuldade para colocar em prática essa experiência interprofissional, mas ver o resultado da prática colaborativa é motivador, eu vejo que são sementinhas crescendo. (E5).

Os depoimentos apontam que, apesar das dificuldades enfrentadas, o cuidado interprofissional possibilita uma assistência abrangente e integrada, permitindo ao profissional enxergar e resolver outras demandas de saúde do usuário. Tal característica, organizadora dos serviços, tende a aumentar a resolutividade das intervenções e a qualidade da atenção à saúde, uma vez que minimizam as omissões e duplicações do cuidado e também diminuem as esperas e os adiamentos desnecessários. Ainda referem que este é um caminho sem volta. 
É um processo muito bonito porque a gente pega o fio isolado e vai tecendo, é um caminho a ser percorrido meio que sem retorno, não vejo a possibilidade de um retrocesso. (E2).

Depois que a gente trabalha assim não tem mais como voltar a trabalhar de forma, existe uma satisfação em ver o residente articulando, pensando em rede, pensando em equipe. (E4).

Essa ideia de caminho sem volta está estreitamente relacionada com o desenho da interprofissionalidade de beneficiar o usuário, benefício este que causa transformações no serviço perceptíveis ao munícipe. Os tutores colocam a resolutividade do cuidado como fruto desse tipo de trabalho, referindo estar diretamente relacionada com o vínculo usuário-equipe que propicia.

Mesmo com todos os benefícios oriundos do trabalho interprofissional, ainda se encontram muitos obstáculos para sua efetivação devido aos desafios impostos por essa prática. Ensinar a trabalhar de forma interdisciplinar e interprofissional parece ser uma tarefa desafiadora para os tutores, tanto por limites do ser humano como pelas limitações profissionais e institucionais.

A cristalização dos serviços é um impeditivo, parece que cada serviço é um pequeno castelo, que não conversa com o outro, e assim se torna um grande desafio transpor essas barreiras. (E10).

Tem também as questões de limitação humana, relações humanas não é uma coisa fácil, as vezes colocar toda essa gente junto pode virar um balaio de gato, mas que sem dúvida com o devido preparo pode virar uma cesta de flores. (E6).

Indubitavelmente, é desafiador trabalhar com diversos profissionais, diversas visões sobre um único fato ou fenômeno, pois há uma linha tênue entre os pensamentos e ações de cada categoria profissional e, ao mesmo tempo, um abismo. Assim, o estabelecimento de pontes entre posições inicialmente antagônicas é o grande desafio da promoção de uma prática colaborativa.

Por fim, pode-se dizer que a adoção do trabalho interprofissional nos serviços envolve a compreensão da complexidade desse fenômeno, além de mudanças organizacionais e do processo de trabalho, entendido desde as relações entre os profissionais até as condições da estrutura social e econômica que as várias organizações compartilham.

\section{Discussão}

A interdisciplinaridade e o trabalho interprofissional ainda são insipientes nas universidades brasileiras, que mantêm hegemonicamente um padrão de ensino uniprofissional e tradicional. Contudo, algumas iniciativas têm-se revelado como potenciais espaços de educação interprofissional, proporcionando experiências de treinamento conjunto e aprendizagem compartilhada (BATISTA, 2012; PEDUZZI ET AL., 2013).

A implantação desse novo modelo desperta receios e inseguranças quanto ao seu manejo, principalmente relativos ao rompimento com o paradigma do ensino tradicional centrado em conteúdos. Entretanto, é latente a necessidade e importância da educação e do trabalho interprofissional serem instituídos, haja vista a diferença positiva que proporcionam ao usuário e aos profissionais envolvidos (SILVA, 2011).

A interprofissionalidade, além de não comportar o processo de trabalho apenas multiprofissional, modo com o qual os profissionais trabalham há anos, é um modelo que demanda uma atuação permeada por dúvidas, questionamentos e interferências, que repercutem em reflexões contínuas e aprimoramento de um processo de cooperação.

Esta cooperação não é somente partilhar o conhecimento, trabalhar em equipe. 
No trabalho multiprofissional, também se trabalha em equipe, porém não há a incorporação de pensamentos e atitudes que vão além de sua profissão, mas somente o auxílio daquele profissional no transcorrer do Projeto Terapêutico Singular (FURTADo, 2007; POMBO, 2005).

Barr et al. (2005) afirmam que a educação interprofissional auxilia na formação de profissionais de saúde mais abertos à prática colaborativa e ao reconhecimento da interdependência das áreas, sendo que tais características se sobressaem à competição e à fragmentação. Destaca-se, então, a importância de uma educação nesses moldes para todos os profissionais de saúde, já que a integralidade do cuidado é um princípio do SUS, modelo de saúde instituído no País.

Observa-se, na fala dos tutores, a importância da vivência do trabalho interprofissional, colocada como fator determinante no aprendizado desse novo modelo. Segundo Furtado (2007), a discussão sobre integração de práticas e saberes tem início, de fato, a partir do momento em que se incorpora (ou se tenta incorporar) tais princípios nas práticas das equipes, donde emergirão questões cuja complexidade e teor fomentarão sobremaneira as discussões sobre o tema.

Dessa maneira, o Programa de Residência Multiprofissional, como modelo de aprendizado na prática, possibilita a sensibilização e introjeção do trabalho interprofissional tanto para os residentes como para os demais envolvidos: tutores, professores, preceptores e gestores.

Apesar dessa percepção positiva dos tutores, estes não apresentam segurança em definir conceitualmente a interprofissionalidade. Os resultados mostram que as palavras interdisciplinaridade e interprofissionalidade ainda causam dúvidas quanto ao seu significado.

Diferenciadas pelo sufixo, 'disciplinaridade' e 'profissionalidade' ilustram, respectivamente, as disciplinas e as profissões, exemplificando a cooperação entre as disciplinas e a colaboração dos profissionais. Ambas, teoria e prática, andam juntas e dividem o mesmo espaço com a multidisciplinaridade e o trabalho multiprofissional tecendo, assim, a linha tênue entre os prefixos 'multi' e 'inter' (SILVA, 2011).

A afirmação de Pombo (2005) mostra-se atual, quando refere que as pessoas se sentem perdidas diante das palavras multi, pluri, inter e trans, disciplinaridade, profissionalidade, e que as fronteiras desses conceitos não estão bem estabelecidas nem entre os estudiosos. O que também pode ser evidenciado em outros estudos, conforme refere Costa (2007) ao realizar uma pesquisa com profissionais da área da saúde que também revelou a dificuldade dos sujeitos com a conceituação desses termos.

Ainda discutindo os resultados, destaca-se o aprendizado que os tutores referem ter obtido ao participar dessa experiência, considerando que, apesar dos desafios, a vivência resultou em um crescimento significativo, que permitiu a contemplação de novos horizontes.

Ademais, torna-se oportuno aludir sobre a educação interprofissional em saúde, considerada a principal estratégia para formar profissionais aptos para o trabalho em equipe, prática essencial para a integralidade no cuidado em saúde. Essa proposta de formação vem sendo discutida nos últimos 30 anos, especialmente nos Estados Unidos e Europa, com o intuito de estimular o aprimoramento do cuidado em saúde por meio do trabalho em equipe.

Os princípios da educação interprofissional se aplicam tanto para a graduação das diferentes profissões de saúde quanto para a educação permanente dos profissionais componentes de uma equipe de trabalho. Segundo Batista (2012), a educação interprofissional em saúde consiste na inversão da lógica tradicional da formação em saúde - cada profissão pensada e discutida em si - abrindo espaço para a 
discussão do interprofissionalismo. É uma proposta na qual profissões aprendem juntas sobre o trabalho conjunto e sobre as especificidades de cada uma. Para o autor, nessa proposta, a valorização da história de diferentes áreas profissionais, a consideração do outro como parceiro legítimo na construção de conhecimento, com respeito pelas diferenças em um movimento de busca, diálogo, desafio, comprometimento e responsabilidade são componentes essenciais.

Ao passo que se busca alterar o processo tradicional de formação, o diálogo com as práticas de professores e tutores deve também ser inserido, pois estes com suas histórias de formação, pautadas na especialização disciplinar, confrontando-se com seus desejos e possibilidades de aprenderem a ensinar de um novo modo mais participativo, interativo e criativo, tal como é a educação interdisciplinar.

Assim também é novo para os docentes saírem da métrica disciplinar e se colocarem no diálogo com colegas oriundos de outros campos disciplinares, relativizando suas certezas e acreditando ser possível e necessário abrir-se para novos caminhos.

\section{Conclusão}

Conclui-se este estudo compreendendo-se o valor do processo de ensino-aprendizado no contexto da formação interdisciplinar e interprofissional, que parece ser potencialmente transformadora da formação em saúde.

Por meio das categorias analíticas, a experiência dos tutores mostrou-se positiva apesar dos desafios impostos. Para os participantes, grande foi o processo de ensino-aprendizado da formação interdisciplinar e interprofissional no Programa de Residência Multiprofissional em Atenção à Saúde, configurando-se em uma importante vivência profissional.

Estudar esse tema, tendo a possibilidade de vivenciá-lo na prática, foi indubitavelmente também uma grande oportunidade de aprendizado. Portanto finaliza-se este estudo parafraseando Lorossa e Kohan (2012) ao referirem que se educa para transformar o que se sabe, não para transmitir o já sabido. Se algo motiva a educar é a possibilidade de que esse ato permite abrir mão de certas verdades, de modo a deixar de ser o que se é para ser outra coisa para além do que se vinha sendo. 


\section{Referências}

BARDIN. L. Análise de Conteúdo. Lisboa: Edições 70, 2009.

BARR, H. (Org.). Interprofessional education: today, yesterday and tomorrow: a review. Londres, UK Centre of the Advancement of Interprofessional Education, 2005. Disponível em: <http://www.unmc.edu/bhecn/documents/ipe-today-yesterday-tmmw-barr.pdf > . Acesso em: 24 out. 2016.

BATISTA, N. A. Educação Interprofissional: concepções e práticas. São Paulo: Caderno FNEPAS, 2012.

COSTA, R. P. Interdisciplinaridade e equipes de saúde: concepções. Mental, Barbacena, v. 5, n. 8, p. 107-124, jun. 2007.

COSTA NETO, P. E. W.; BATISTA, S. H. A preceptoria na formação em saúde: uma incursão na literatura. In: SILVA, G. T. R. (Org.). Residência multiprofissional em saúde: vivências e cenários da formação. São Paulo: Martinari, 2013. p. 47-60.

FELICIANO, A. B. et al.. A Residência em Saúde da Família e a Comunidade da UFSCAR: desafio do desconhecido para a formação do trabalhador para o SUS. In: SILVA, G. T. R. (Org.). Residência Multiprofissional em Saúde: vivências e cenários da formação. São Paulo: Martinari, 2013. p. 82 -108.

FURTADO, J. P. Equipes de referência: arranjo institucional para potencializar a colaboração entre disciplinas e profissões. Comunic., Saúde, Educ., Botucatu, v. 11, n. 22, p. 239-255, 2007

LOROSSA, J.; KOHAN, W. O Mestre Ignorante: cinco lições sobre a emancipação intelectual. Belo Horizonte: Autêntica, 2012.

LÜDKE, M.; ANDRÉ, M. E. D. A. Pesquisa em Educação: abordagens qualitativas. São Paulo: Editora Pedagógica e Universitária, 2008.
MCKINLAY, J. B. Health promotion throug healthy public policy: the contribution of complementary research methods. Can J Public Health, Quebec, v. 83, supl. 1, p. 11-9, mar./abr. 2012.

MINAYO, M. C. S. O desafio do conhecimento: pesquisa qualitativa em saúde. 9. ed. São Paulo: Hucitec, 2006.

PEDREIRA, C. L. et al. Experiência da Residência Multiprofissional do Hospital universitário/UFBA nas Unidades de Saúde da Família. In: SILVA, G. T. R. (Org.). Residência Multiprofissional em Saúde: vivências e cenários da formação. São Paulo: Martinari, 2013. p. 109-154.

PEDUZZI, M. et al. Educação interprofissional: formação de profissionais de saúde para o trabalho em equipe com foco nos usuários. Rev Esc Enferm USP, São Paulo, v. 47, n. 4, p. 977-983, 2013.

POMBO, O. Interdisciplinaridade e integração dos saberes. Liinc, Rio de Janeiro, v. 1, n. 1, p. 3-15. 2005.

SILVA, R. H. A. Educação interprofissional na graduação em saúde: aspectos avaliativos da implantação na Faculdade de Medicina de Marília (Famema). Educ. Rev., Curitiba, n. 39, p. 159-175, abr. 2011.

\footnotetext{
Recebido para publicação em janeiro de 2016

Versão final em setembro de 2016

Conflito de interesses: inexistente

Suporte financeiro: não houve
} 